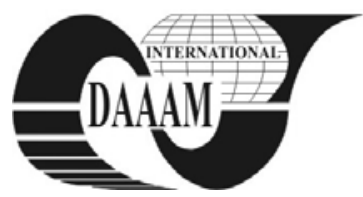

\title{
DEMONSTRATION OF OPERATING DATA ANALYSIS BY BUSINESS INTELLIGENCE DEVELOPMENT STUDIO
}

\author{
PROKOPOVA, Z[denka]; SILHAVY, P[etr] \& SILHAVY, R[adek]
}

\begin{abstract}
The main aim of the paper is to present demonstration of operating data analyses with regard to availability of suitable tools for end - users. Concretely we present utilization of SQL Server Analysis Services as a key component for data analysis. For multidimensional data analysis enabling loading, questioning and administration of data cubes we used OLAP module created by Business Intelligence Development Studio.
\end{abstract}

Key words: data analysis, business intelligence, data cube, datawarehouse

\section{INTRODUCTION}

More and more companies and institutions store enormous amounts of data, it means create archives of tables, documents and multimedia objects (images, audio recordings, video clips, scanned documents etc.). Almost all manufacturing and business processes are someway saved in database structures, in to which every day flow next thousands entries. It is very easy to collect huge volumes of data but very hard to pull useful facts out of the heap. Imposition of analytical tools is obtaining the information from collected data and leading them over to the form, usable for following control and decision making (Berthold \& Hand, 2007), (Berthold et al., 2010).

Business information systems depth data analysis and their subsequent utilization at company control fall under common mark - Business Intelligence. The term Business Intelligence was introduced by analyst Howard J. Dresner in the year 1989. He described them as a set of concepts and methods intended for improving the quality of analytical and decision-making processes in organizations. He focused on importance of data analysis, reporting and query tools, which offer to user amount of data and help him with synthesis of valuable and useful information. Analytical and planning character of Business Intelligence applications differ from the ordinary operating systems in user's look on data. While operating systems work with detailed information analytic exercises work with aggregate data. So that we might realize the analytical look it was necessary to change data access technology. Operating systems work with transaction entity-relational databases analytical systems work with data warehouses and multidimensional databases (Bjorklund, 2010).

From the manufacturing processes point of view it is interesting utilization of data mining, data warehouses, OLAP (Business Intelligence) at analysis of technological process stage, prediction and diagnostic of abnormal stages and looking for technological connections in historical data rising as a secondary product of monitoring. As an example is mentioned utilization of SQL Server Analysis Services as a suitable tool for end - users (Pokorna, 2010), (Prokopova et al., 2011). For the purpose of multidimensional data analysis enabling creation and administration of data cubes we used OLAP module created by Business Intelligence Development Studio (BIDS) (Larson, 2009), (Webb et al., 2009).

\section{DATA PREPARATION}

At the beginning we had data in various formats of Excel tables. It was necessary to sort data and design uniform structure.

On the ground of utilization of analytical tools for data analyses we created data warehouse with several tables of facts and several tables of dimensions. For interlocking of connections among tables of dimensions and tables of facts it was necessary to prepare and create all needed tables of keys.

\section{DATA CUBE CREATION}

Data cube creation by Business Intelligence Development Studio consists of next steps:

- Definition of data sources

- Definition of the data source view

- Design of the data cube

- Dimensions configuration

- $\quad$ The data cube equalization

If we want to create a new project we must choose Analyses Service project from the menu. After definition of name and location of the new project it will open the window of development environment for data cube modeling as we can see on the Fig. 1.

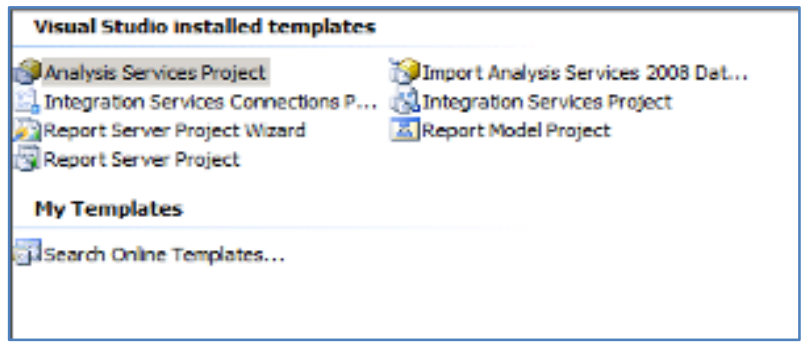

Fig. 1. Project creation in BIDS

\subsection{Definition of data sources}

The first step in a data cube modeling is creation of Data sources. A data source refers to the database, from which project approaches to data. A data source can be connected with any database available by OLE DB or ODBC.

A data source can be defined in Solution Explorer window where we can choose offered data source or we can create a new one by Data Source Wizard. In the case of creation of new data source we have to choose server, database, and type of desired security.

\subsection{Definition of the data source view}

As in the previous case we can use Data source View Wizard. In the first step the appropriate data source is chosen. Then we choose needed tables from which data source consists of. The next step of completing the wizard is providing the new data source by the name. 
After the wizard finishing we have the new data source view (as dsv file). In the same time is appearing the structure of data diagram in the design window. There are tables of dimensions, tables of facts and their connections as we see on Fig. 2.

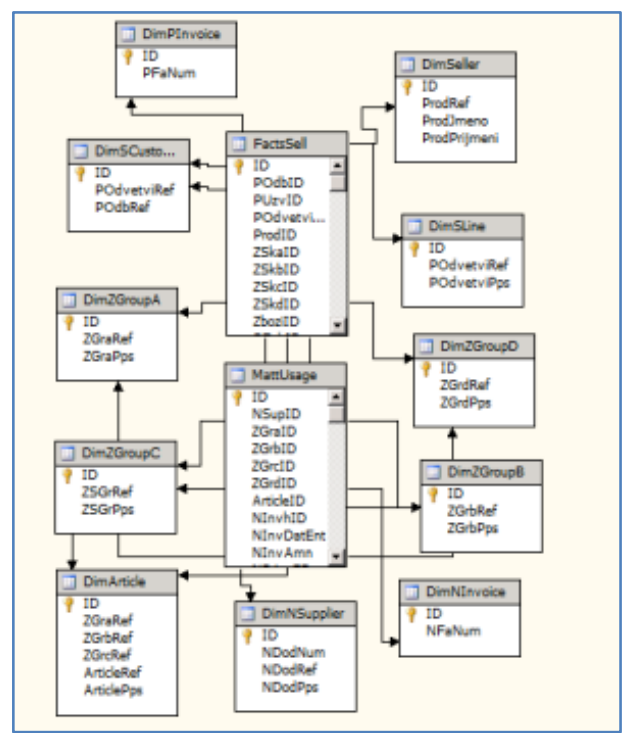

Fig. 2. Setting of Data Source View

\subsection{Definition of the data cube}

The last step is the Data cube composition. In this step it is possibility to use wizard once again and create new data cube. In the first step is necessary to choose way of the data cube creation. We can create empty data cube by the help of the data source. After that we ought to choose measures from tables of facts and dimensions from tables of dimensions. Demonstration of new data cube composition is shown on Fig. 3.

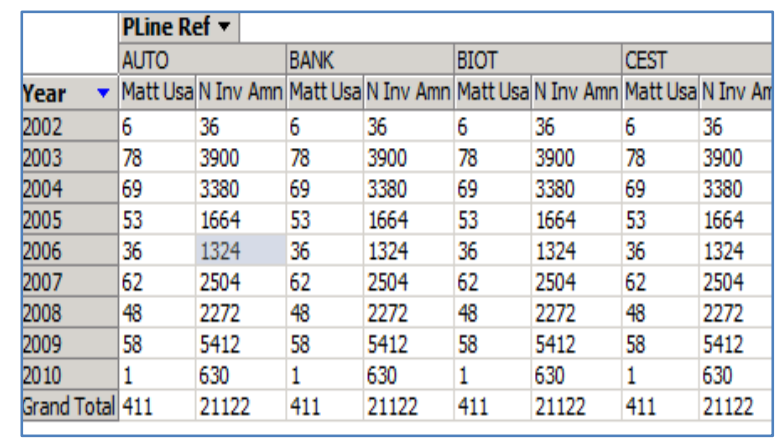

Fig. 3. Data Cube composition

\subsection{Dimensions configuration}

The last step before project publication is dimension configuration. In this phase are characteristics set up and hierarchies defined. Adjustment is providing in Dimension Designer which serves firstly to end users.

\subsection{The data cube equalization}

Final phase of project consists of two parts. First part Build covers development and preliminary tuning on local developer computer, second part Deploy boots debugged program to analytical server and hand down him to end users. End user can choose between access of thick client, when client application runs on their local computer (MS Excel, Report Builder) and thin client, which employs web browser for approach to server application and data. In the event of thick client there is not so big server loading as in the case of thin client, because computation achievement divides between local computer and a server. For thin client all application logic is on server and its computational possibilities are unused.
Completed Data Cube we can see in browser environment or we can draw it for better understanding as a three dimensional cube. For visualisation see figure Fig. 4.
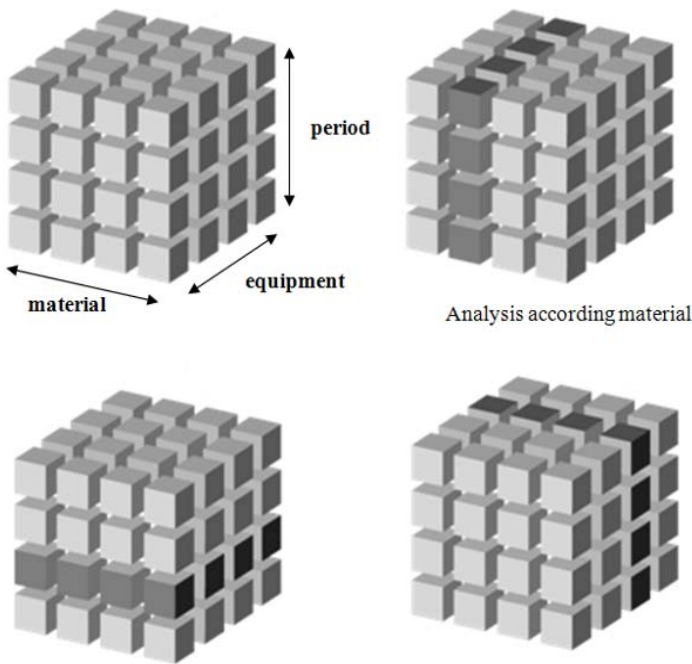

Analysis according time period

Analysis according equipment

Fig. 4. Graphical interpretation of data analysis by the help of 3-dimensional data cube

\section{CONCLUSION}

High - quality data analysis and level of gained information stands on background of all correct manager decisions. Good managers are able to use it for improvement of efficiency and company competitive advantage by prediction of trends and future development tendencies. With the aid of deep data analysis and data mining we would like to disclose the manufacturing process anomaly and focus on suitable conditions of production and market.

\section{ACKNOWLEDGEMENTS}

This work was supported by the Ministry of Education of the Czech Republic in the range of the project No. MSM 7088352102 .

\section{REFERENCES}

Berthold, M. R.; Hand, D. J. (2007). Intelligent Data Analysis. Springer, ISBN: 978-3540430605, Berlin

Berthold, M. R.; Borgelt, C.; Höppner, F.; Klawonn, F. (2010). Guide to Intelligent Data Analysis. Springer, ISBN: 978-184882-259-7, London

Bjorklund, S. (2010). Utilisation of Data Mining Principles in Maintenance Planning. In: Annals of DAAAM for 2010 \& Proceedings of the 21st International DAAAM Symposium, Zadar, pp. 0753-0754, Published by DAAAM, ISSN 17269679, ISBN 978-3-901509-73-5, Vienna.

Larson, B. (2009). Delivering Business Intelligence with Microsoft SQL Server 2008. McGraw-Hill Osborne, ISBN: 978-0071549448

Prokopova, Z.; Silhavy, P.; Silhavy, R. (2011). Preview Of Methods And Tools For Operating Data Analysis. International Journal of Mathematical Models And Methods In Applied Sciences. No. 6, Vol. 5. pp.1102-1109. ISSN: 1998-0140

Pokorna, D. (2010). Business Data Analyses Possibilities. Diploma thesis. Faculty of Applied Informatics, Tomas Bata University in Zlín

Webb, C.; Russo, M.; Ferrari, A. (2009). Expert Cube Development with Microsoft SQL Server 2008 Analysis Services. Packt Publishing, ISBN: 978-1847197221 